\title{
EMISSÃO DE BENZENO, TOLUENO, ETILBENZENO E XILENOS EM MOTOCICLOS ABASTECIDOS COM DIFERENTES MISTURAS DE COMBUSTÍVEL
}

\author{
Valeria Macedo ${ }^{1}$, Luiz Carlos Daemme ${ }^{1}$, Marina S. Nadolny ${ }^{1}$, Renato Penteado ${ }^{1,2}$, \\ Sergio Machado Corrêa ${ }^{3}$ e Fabiola Dayane Netto ${ }^{1}$ \\ ${ }^{1}$ Institutos Lactec \\ ${ }^{2} \mathrm{P} \& \mathrm{~K}$ Consultoria \\ ${ }^{3}$ Universidade do Estado do Rio de Janeiro - UERJ
}

\begin{abstract}
E-mails: valeria.macedo@lactec.org.br, luiz.carlos@lactec.org.br, Marina marina.nadolny@lactec.org.br, renato@lactec.rg.br, sergiomc@uerj.br, fabiola.netto@lactec.org.br,
\end{abstract}

\section{RESUMO}

O presente artigo tem como objetivo comparar as emissões de benzeno, tolueno, etilbenzeno e xilenos (BTEX), além das emissões de poluentes legisladas (THC, CO, $\mathrm{NO}_{\mathrm{x}}$ ) em três motociclos. Os veículos foram abastecidos com combustível de referência - gasolina A22, sendo que um deles, flexfuel, foi abastecido também com Etanol Hidratado de Referência (EHR) e mistura na proporção de $50 \%$ de A22 e EHR. As emissões regulamentadas foram medidas respeitando procedimentos de medições normalizados. Para análise dos BTEX foi utilizada a técnica analítica de espectrometria de massas. Para determinar a influência do catalisador, as emissões de BTEX foram medidas com e sem o catalisador em um dos motociclos. Tendo em vista a adoção do ciclo WMTC (Worldwide Motorcycle Test Cycle) em substituição ao EURO (Diretiva Europeia 97/24/EC), também foram medidas as emissões em ambos os ciclos, e os resultados foram comparados. Os principais resultados mostraram que o tolueno apresenta a maior emissão quando comparada aos outros BTEX. O uso do catalisador propicia uma redução global das emissões de BTEX de 69\%. A condução no ciclo WMTC tende a emitir menor teor de emissões legisladas e BTEX, com exceção ao $\mathrm{NO}_{\mathrm{x}}$, quando se compara ao ciclo EURO.

\begin{abstract}
The article presents results of a comparison study focused on emissions of benzene, toluene, ethylbenzene and xylenes (BTEX), as well as THC, CO and $\mathrm{NO}_{\mathrm{x}}$, in three motorcycles. The vehicles were fueled with the reference fuel - gasoline A22. One motorcycle was fueled with reference hydrated ethanol (EHR) blended in the proportion of 50\% (A22) and 50\% (HER). Regulated emissions were measured according with standard procedures. BTEX were measured by mass spectrometry. To determine the influence of the catalyst, the emission of BTEX were measured with and without the catalyst in one motorcycle. Due to the entrance of the WMTC cycle (Worldwide
\end{abstract}


Motorcycle Test Cycle) to replace the EURO (European Directive 97/24/EC), emissions were also measured in both cycles, and the results were compared. The main results show that toluene has the highest concentration of emission compared to other compounds of the BTEX group. The use of the catalyst contributes to a global BTEX reduction of $69 \%$. Driving on WMTC cycle tends to deliver lower content of legislated emissions and BTEX, except $\mathrm{NO}_{\mathrm{x}}$, compared to EURO cycle.

\section{INTRODUÇÃO}

Os problemas provenientes da poluição atmosférica começaram a ser identificados após a revolução industrial e constituem uma das mais graves ameaças à qualidade de vida do homem, da fauna e flora. As atividades humanas são poluidoras e, com frequência, poluentes delas resultantes são lançados ao meio ambiente, principalmente pela urbanização, crescimento da população, desenvolvimento de novas tecnologias e uma elevada frota de veículos automotores [1].

Os poluentes emitidos na atmosfera podem ser de origem natural ou antropogênica, e são divididos em primários, quando emitidos diretamente por uma fonte, e secundários, quando formados na atmosfera através de reações químicas térmicas e fotoquímicas entre poluentes primários e os constituintes naturais da atmosfera. As fontes são basicamente duas: fixas (indústrias, usinas, incineradores de resíduos) e móveis (meios de transporte) [2].

Em 1986 foi criado o PROCONVE (Programa de Controle da Poluição do Ar por Veículos Automotores) com o objetivo de reduzir e controlar a contaminação atmosférica por fontes móveis (automóveis, caminhões, ônibus e máquinas rodoviárias e agrícolas) fixando prazos, limites máximos de emissão e estabelecendo exigências tecnológicas para veículos automotores, nacionais e importados. Para complementar o controle do PROCONVE e reduzir a poluição do ar por motocicletas, em 2002 foi criado o Programa de Controle da Poluição do Ar por Motociclos e Veículos Similares PROMOT [3, 4].

Nas cidades, as emissões veiculares desempenham um papel de destaque no nível de poluição do ar, pois emitem gases como: compostos orgânicos voláteis (COVs), monóxido de carbono $(\mathrm{CO})$, óxidos de nitrogênio $\left(\mathrm{NO}_{\mathrm{x}}\right)$, óxidos de enxofre $\left(\mathrm{SO}_{\mathrm{x}}\right)$, gases ácidos, entre outros. Dentre os compostos orgânicos voláteis destacam-se os BTEX (benzeno, tolueno, etilbenzeno, o-xileno, m-xileno e p-xileno) [5].

Existe uma ampla variedade de COVs presentes na atmosfera como gases e partículas de origem natural que são produzidos pela decomposição de matéria orgânica e de origem antropogênica, emitidos através das atividades humanas oriundas da evaporação ou combustão de combustíveis fósseis do setor de transportes, sendo o BTEX um dos principais COVs, além de álcoois, cetonas, aldeídos, alcanos e alcenos. Estes compostos (BTEX) não estão contemplados na Resolução CONAMA 03/90, no entanto alguns deles apresentam limites para exposição ocupacional (limites de emissões de poluentes em ambientes de trabalho que favoreçam o surgimento de doenças) e para emissões de fontes fixas [6]. 
Do ponto de vista ambiental, os BTEX têm um papel de destaque como poluentes primários, sendo os combustíveis fósseis a principal fonte de emissão através de veículos automotores leves, movidos à gasolina. São considerados uns dos principais precursores de ozônio, além de causarem sérios danos à saúde [7].

A principal via de absorção do BTEX é a pulmonar, seguida pela oral que é mais eficiente com relação à dose ingerida. No entanto, o contato de vapores desses hidrocarbonetos pela pele tem consequências menos significativas [6].

Pela importância da qual se revestem os efeitos provocados pela presença de BTEX no meio ambiente, governos, universidades e pesquisadores têm dedicado estudos sobre o assunto. Este artigo apresenta os resultados de uma pesquisa com ênfase nestes poluentes realizada em um laboratório de emissões veiculares. A partir da pesquisa bibliográfica foi possível verificar que a maioria dos trabalhos existentes sobre esses compostos estão relacionados com sua presença no ar ambiente, geralmente em locais com fluxo de tráfego intenso como: postos de combustíveis, ambientes de trabalho e vias urbanas. No entanto, são poucos os estudos que se preocupam em analisar a emissão coletada diretamente do escapamento de veículos automotores, que é o foco deste trabalho.

Em 2008, Yung-Chen et al. [8], publicaram um estudo sobre os efeitos dos teores de enxofre e aromáticos contidos na formulação da gasolina sobre as emissões de poluentes de motociclos. O estudo teve o objetivo de avaliar os compostos $\mathrm{CO}$, THC e $\mathrm{NO}_{\mathrm{x}} \mathrm{e}$ também cinco principais componentes tóxicos do ar. Para o estudo foi utilizada uma motocicleta com motor de quatro tempos e 8 misturas de gasolina divididas em 4 grupos contendo na formulação valores de $149 ; 146 ; 48,5$ e 40,5 ppm de enxofre. Também foram analisados combustíveis contendo 28,6;22,0;29,0 e 21,0\% (em volume) de compostos aromáticos. A coleta das amostras foi realizada durante os ensaios dinamométricos com base no ciclo Europeu e as amostras de ar foram identificadas e quantificadas por um espectrômetro de massas acoplado a um cromatógrafo de fase gasosa. Os resultados deste trabalho foram baseados na correlação entre composições de combustível e as emissões de poluentes do ar. A redução do teor de enxofre no combustível não apresentou melhora significativa com relação às emissões de $\mathrm{CO}$, THC ou $\mathrm{NO}_{\mathrm{x}}$. Constatou-se, no entanto, que a redução do teor de aromáticos diminui as emissões de THC e aumenta as emissões de $\mathrm{NO}_{\mathrm{x}}$. Estes resultados demonstram que as emissões de poluentes são influenciadas pela concentração de aromáticos no combustível em uma proporção maior que o teor de enxofre. Em relação aos gases tóxicos, a redução de aromáticos no combustível diminuiu as emissões de benzeno e tolueno e aumentou as emissões de aldeídos. Os autores concluíram que o benefício da redução de emissões devido a mudanças na composição combustível em motocicletas pode ter impactos significativos na análise de risco para a saúde.

Em 2012, CORREA et al. [9], realizaram um trabalho referente ao impacto das emissões de BTEX em postos de abastecimento para a atmosfera. Foram avaliados onze postos de gasolina localizados na cidade do Rio de Janeiro. Para coleta das amostras foram utilizados cartuchos de carvão ativo. Nove amostras foram coletadas em vários intervalos de tempo totalizando 50 amostras que foram analisadas utilizando um cromatógrafo de fase gasosa acoplado a um detector seletivo de massas. Os resultados apresentados neste estudo mostraram que as concentrações de aromáticos no ar ambiente de postos de gasolina foram sensivelmente superiores aos valores médios em locais com alto fluxo veicular. 
Em 2015, Li et al. [10], realizaram um estudo das emissões evaporativas e de escape em três motocicletas quatro tempos, que foram abastecidas com E10 e gasolina, testadas em banco de chassis. Os autores observaram que o THC reduz com uso do etanol e o tolueno possui uma maior concentração com relação aos outros compostos.

\section{METODOLOGIA}

O plano de ensaios contemplou a realização de no mínimo três ensaios válidos, de modo a permitir uma análise estatística dos resultados. As emissões regulamentadas foram definidas pelo PROMOT: THC, $\mathrm{CO}$ e $\mathrm{NO}_{x}$, respeitando técnicas de medições tradicionais. Para análise dos BTEX foi utilizada a técnica analítica de cromatografia de fase gasosa acoplada a espectrometria de massas com o objetivo de identificar e quantificar os compostos.

\section{a) Ensaios legislados}

Os ensaios legislados foram realizados em um laboratório de emissões veiculares, que possui estrutura e equipamentos que atendem às especificações das normas definidas pelo CONAMA para homologação de motociclos: a diretiva 97/24/EC (ciclo EURO) e a norma ABNT NBR 16369 (ciclo de condução transiente WMTC - "Worldwide Motorcycle Test Cycle"). Em ambas as diretivas o veículo ciclomotor é colocado sobre um dinamômetro de chassis que lhe aplica cargas em um trajeto que simula condições de tráfego urbano, sendo a principal diferença entre as metodologias, a característica dos ciclos e número de fases [11], conforme pode-se observar na figura 1. Observa-se no ciclo WMTC um perfil de maior exigência do motociclo durante o ensaio, porém essa característica também favorece um rápido aquecimento e manutenção da temperatura do catalisador.

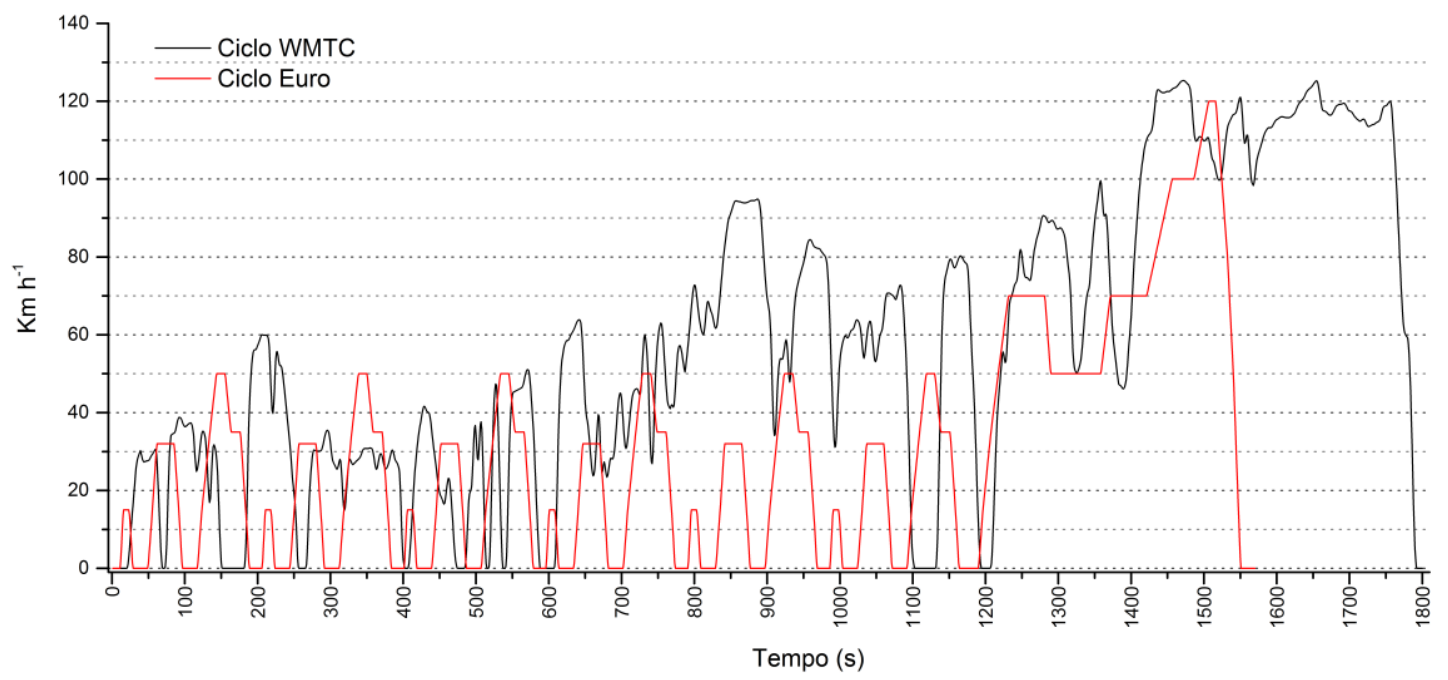

Figura 1 - Ciclos de velocidades em função do tempo para ensaios de emissões em motociclos. ciclos EURO e WMTC.

No ciclo EURO o trajeto é divido em duas fases. Motociclos dotados de motores com volume de deslocamento (cilindrada) de até $150 \mathrm{cc}$ são testados apenas na primeira fase (ciclo urbano), com duração de 1170 s. Àqueles com cilindrada superior aplica-se além do ciclo urbano, uma segunda fase, com $400 \mathrm{~s}$, denominada extra urbana com velocidades que atingem $120 \mathrm{~km} / \mathrm{h}$. As distâncias percorridas em cada fase são de 
aproximadamente de $6,0 \mathrm{~km}$. O ciclo WMTC, de característica transiente, possui até três fases, cada uma com $600 \mathrm{~s}$. A norma define que podem ser usadas uma, duas ou três fases, em função da velocidade máxima desenvolvida pelo motociclo, combinada com a capacidade volumétrica do motor [11].

\section{b) Ensaios não legislados}

As coletas das amostras de BTEX foram realizadas paralelamente ao ensaio de emissões por meio de um sistema de amostragem. Foi colhida uma amostra diluída dos gases de escapamento, com uso de um amostrador de volume constante (AVC), coletada de forma contínua durante todo ensaio em cartuchos de carvão ativo, usando um sistema de amostragem utilizado pelo laboratório para coletas de aldeídos conforme representado na figura 2.

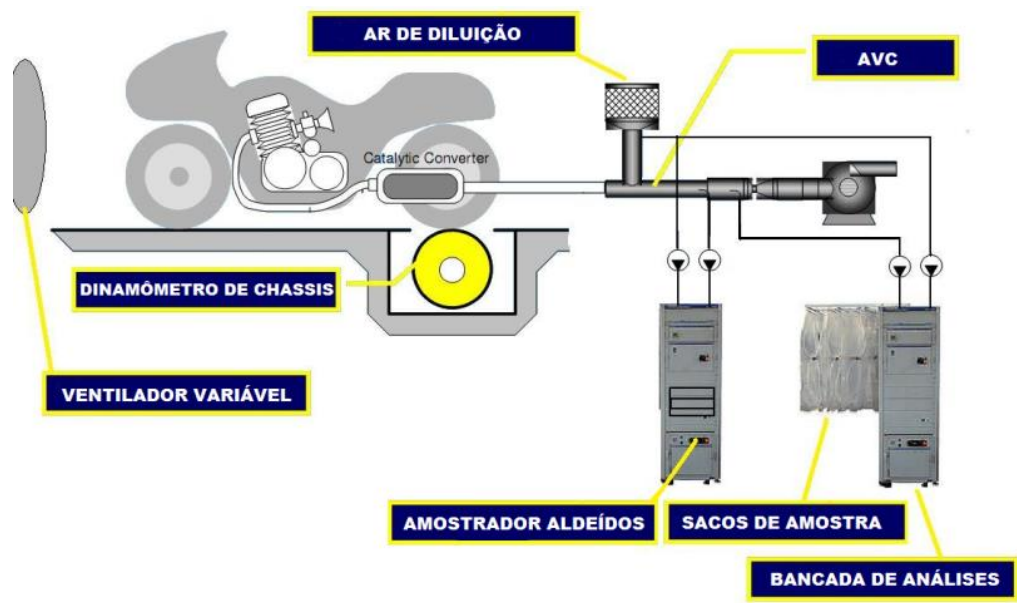

Figura 2 - Esquema da execução de ensaio de emissões utilizando o sistema de amostragem FONTE: DAEMME et al. [11].

\section{Amostragem}

O preparo ocorreu com a instalação de um cartucho em um sistema de amostragem para aldeídos, respeitando a direção de fluxo indicado pelo fabricante, e com uma vazão regulada para 1,0 L/min. Em seguida, foi realizado um teste de verificação de vazamentos no cartucho. Foi usado um cartucho para cada fase do ciclo de condução e um cartucho para coleta do ar de diluição (ar ambiente). O cartucho de carvão ativo utilizado foi de leito duplo (400/200 mg, Supelco Orbo 32), com leito principal de 100 $\mathrm{mg}$ e leito de segurança de $50 \mathrm{mg}$.

\section{Extração}

Para iniciar o procedimento de extração, um microlitro de $100 \mathrm{ng} \mathrm{mL} \mathrm{m}^{-1}$ de tolueno deuterado foi adicionado com uma micro seringa no interior do cartucho com objetivo de avaliar o processo de recuperação. Em seguida o carvão ativo foi retirado para um vial de $2 \mathrm{~mL}$. O conteúdo de cada cartucho foi colocado em frascos separados, e adicionados $1000 \mu \mathrm{L}$ de diclorometano a uma temperatura de $-20^{\circ} \mathrm{C}$ com o intuito de prevenir a volatilização dos compostos. Os frascos selados foram colocados num banho de ultrassom durante 20 minutos, resfriados e, em seguida, deixados durante 1 hora a $10^{\circ} \mathrm{C}[9]$. 


\section{Análise química}

As amostras foram injetadas num cromatógrafo a gás Varian modelo 450 GC acoplado a um detector seletivo de massa modelo 220 MS com um amostrador automático CombiPAL estático contendo uma coluna VF-5MS $(30 \mathrm{~m}, 0,25 \mathrm{~mm}$ e $0,25 \mu \mathrm{m}$ de espessura de filme). As injeções de $1,0 \mu \mathrm{L}$ de amostra foram realizadas em um injetor a $200^{\circ} \mathrm{C}$, com uma razão de divisão de 1:4, utilizando como gás de arraste hélio a 2,0 mL $\min ^{-1}$. O programa de temperatura do forno começou a $40^{\circ} \mathrm{C}$ que foi mantida durante 3 minutos; isto foi seguido por uma taxa de aquecimento de $15^{\circ} \mathrm{C} \min ^{-1}$ até $200^{\circ} \mathrm{C}$, e a coluna foi mantida a esta temperatura durante 6 minutos. As temperaturas de linha da armadilha de íons, as temperaturas utilizadas na linha de transferência foram $150^{\circ} \mathrm{C}$, $40^{\circ} \mathrm{C}$ e $180^{\circ} \mathrm{C}$, respectivamente. $\mathrm{O}$ detector seletivo de massa de íons monitorados a partir de 72 a 79, 89 a 93 e 101 para 107 e 119 a 121 (m/z) [9].

A calibração foi realizada com uma solução padrão de BTEX (Supelco EPA TO -1 Mix 1A). Para construir a curva de calibração, foram usadas soluções com concentrações variando de 0,1 a $4,0 \mathrm{ng} \mu \mathrm{L}^{-1}$. Os coeficientes de determinação foram sempre acima de 0,99. Utilizando o método dos mínimos quadrados, curvas de calibração foram obtidas, e os limites de detecção e de quantificação foram calculados. Esta informação foi obtida dividindo-se por três a dez vezes a relação sinal-ruído pelos coeficientes lineares das curvas de calibração. O limite de quantificação para cada BTEX calculado foi de 5,6 pg $\mu \mathrm{L}^{-1}[9]$.

\section{c) Especificação dos motociclos}

Foram selecionadas amostras conforme configurações da tabela 1, sendo: M1G, selecionado devido à opção do laboratório em conseguir ensaia-lo com dois tipos de escapamentos, um original com elemento catalisador e outro sem catalisador. Amostra M2G por possibilitar o ensaio nos ciclos EURO e WMTC, este último conforme a norma ABNT NBR 16639, devido às suas características que possibilitaram ensaios em ambos ciclos em sua totalidade de fases e a amostra M3F de $150 \mathrm{cc}$ com motor flexfuel que possibilitou a utilização de combustíveis com diferentes teores de etanol.

Tabela 1 - Características dos motociclos utilizados nos testes de emissões

\begin{tabular}{c|c|c|c|c|c}
\hline Identificação & Fase & Motor (cc) & $\begin{array}{c}\text { Ano de } \\
\text { fabricação }\end{array}$ & Combustível & Catalisador \\
\hline M1Gsc & M3 & 124.9 & 2009 & Gasolina & Não \\
\hline M1G & M3 & 124.9 & 2009 & Gasolina & Sim \\
\hline M2G & M3 & 291.6 & 2010 & Gasolina & Sim \\
\hline M3F & M3 & 149.2 & 2011 & Flexfuel & Sim \\
\hline
\end{tabular}

\section{d) Especificação dos combustíveis}

Para a realização do estudo foram utilizados três combustíveis, definidos com base no consumo nacional e em concordância com as normas utilizadas para ensaios de emissões realizados no Brasil. A norma ABNT NBR 8689 é responsável por padronizar a nomenclatura e as proporções de combustíveis em cada mistura. As resoluções da ANP: 21/2009 [12] e 23/2010 [13] definem as especificações que devem ser atendidas com relação às características e limites da composição, assim como os métodos para análise. As principais características dos combustíveis utilizados constam da tabela 2. Essas informações são resultado das análises de amostras dos combustíveis utilizados 
nos motociclos para realização dos ensaios. Alguns compostos foram analisados através de metodologia própria desenvolvida por um laboratório especializado em análises de combustíveis, entre eles os compostos de BTEX analisados pela técnica de cromatografia em fase gasosa acoplada a espectrometria de massas.

Tabela 2 - Características dos combustíveis utilizados nos testes de emissão veicular

\begin{tabular}{lccc}
\hline Parâmetro & $\mathrm{A} 22$ & $\mathrm{E} 61$ & EHR \\
\hline Enxofre Total $\left(\mathrm{mg} \mathrm{kg}^{-1}\right)$ & 10 & 9,6 & 1,1 \\
Etanol $(\%$ vol.) & 23 & 62 & - \\
Massa Específica a $20^{\circ} \mathrm{C}\left(\mathrm{kg} \mathrm{m}^{-3}\right)$ & 742,7 & 776,1 & 809,9 \\
\hline Cromatografia Detalhada & & $\%$ vol. & N.D \\
\hline Totais Aromáticos & 19,338 & 10,412 & N.D \\
Total C14 + & 0,003 & 0,003 & N.D \\
Total Iso - Parafinas & 29,488 & 13,778 & N.D \\
Total Naftênicos & 4,076 & 2,561 & N.D \\
Total Olefinas & 5,301 & 2,721 & 100,0 \\
Total Oxigenados & 22,774 & 60,912 & N.D \\
Total Parafínicos & 15,280 & 7,248 & N.D \\
Totais Desconhecidos & 3,741 & 2,367 & N.D \\
Benzeno & 0,154 & 0,075 & N.D \\
Tolueno & 13,661 & 7,051 & N.D \\
p-Xileno & 0,304 & 0,009 & N.D \\
$m-$ Xileno & 0,595 & 0,296 & N.D \\
o-Xileno & 0,389 & 0,181 & N.D \\
Etilbenzeno & 0,200 & 0,104 & N.D \\
Outros Aromáticos & 4,035 & 2,696 & \\
\hline N.D.: Valores & & & \\
\hline
\end{tabular}

N.D.: Valores não detectados

\section{e) Metodologia de cálculo e apresentação dos resultados}

Os resultados das análises de BTEX foram disponibilizados em concentração (ppm) e para a conversão em g/km foi adaptado o cálculo existente na norma NBR 16369/2015 Motociclos e veículos similares - Determinação de hidrocarbonetos, monóxido de carbono, óxido de nitrogênio e dióxido de carbono no gás de escapamento - conforme equação abaixo:

$$
B T E X_{\frac{g}{k m} 1}=\left(\frac{V_{e d} \times d_{B T E X} \times\left[B T E X_{e 1}-B T E X_{d 1} \times\left(1-\frac{1}{R D}\right)\right] \times 10^{-6}}{D_{1}}\right) \times F p
$$

Onde:

$\boldsymbol{B T E} \boldsymbol{X}_{\frac{\boldsymbol{g}}{\boldsymbol{k m}} \mathbf{1}}=$ massa dos compostos - BTEX por fase em $\mathrm{g} / \mathrm{km}$

$\boldsymbol{V}_{\boldsymbol{e} \boldsymbol{d}}=$ volume do gás amostrado nas condições de entrada do AVC, corrigido para a condição padrão de temperatura e pressão $(293,15 \mathrm{~K}$ e $101,325 \mathrm{kPa})$

$\boldsymbol{d}_{\boldsymbol{B} T \boldsymbol{E} \boldsymbol{X}}=$ densidade de massa dos compostos - BTEX a $20^{\circ} \mathrm{C} \mathrm{kg} / \mathrm{m} 3$

$\boldsymbol{B T E} \boldsymbol{X}_{\boldsymbol{e} 1}=$ concentração do composto analisado no gás de escapamento diluído, medida no cartucho de carvão ativo, expressa em partes por milhão de carbono $\left(10^{-6} \mathrm{C}\right)$

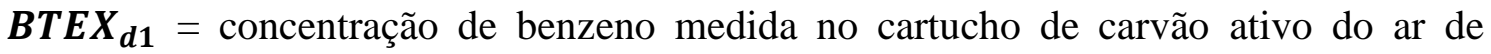
diluição, expressa em partes por milhão de carbono $\left(10^{-6} \mathrm{C}\right)$

$\boldsymbol{R} \boldsymbol{D}=$ Razão de diluição 
$\boldsymbol{D}_{\mathbf{1}}=$ Distância percorrida

$\boldsymbol{F} \boldsymbol{p}=$ Fator de ponderação

Nota: o valor do fator de ponderação, utilizado para o resultado final atribuindo pesos diferenciados a cada fase do ciclo, se deu de acordo com a metodologia empregada no ciclo em que os ensaios foram realizados: Diretiva 97/24/2006 ou ABNT 16369/2015.

\section{ANÁLISE DOS RESULTADOS E DISCUSSÃO}

A figura 3 apresenta as emissões regulamentadas de THC $\mathrm{CO}$ e $\mathrm{NO}_{\mathrm{x}}$ nos motociclos objeto de estudo. Comparando-se as emissões com os limites da legislação vigente, observamos que:

- Todos os motociclos atendem os limites de emissões para o THC, independente do combustível, ciclo ou ausência de catalisador (caso $\mathrm{M}_{1 \mathrm{GC}}$ );

- No tocante as emissões de CO o motociclo M2G apresentou valores acima dos limites previstos na legislação em ambos ciclos em que foi testado;

- Para as emissões de $\mathrm{NO}_{\mathrm{x}}$ apenas o motociclo M1G, quando testado sem catalisador, superou os limites da legislação.

Os compostos de principal interesse desse estudo, BTEX, pertencem ao grupo dos hidrocarbonetos (THC), sendo que essas emissões em todas as amostras estudadas não apresentaram desvios aos limites da legislação. Desta maneira os resultados obtidos para o grupo dos BTEX propiciam um entendimento dessas emissões em veículos com normais condições de uso.

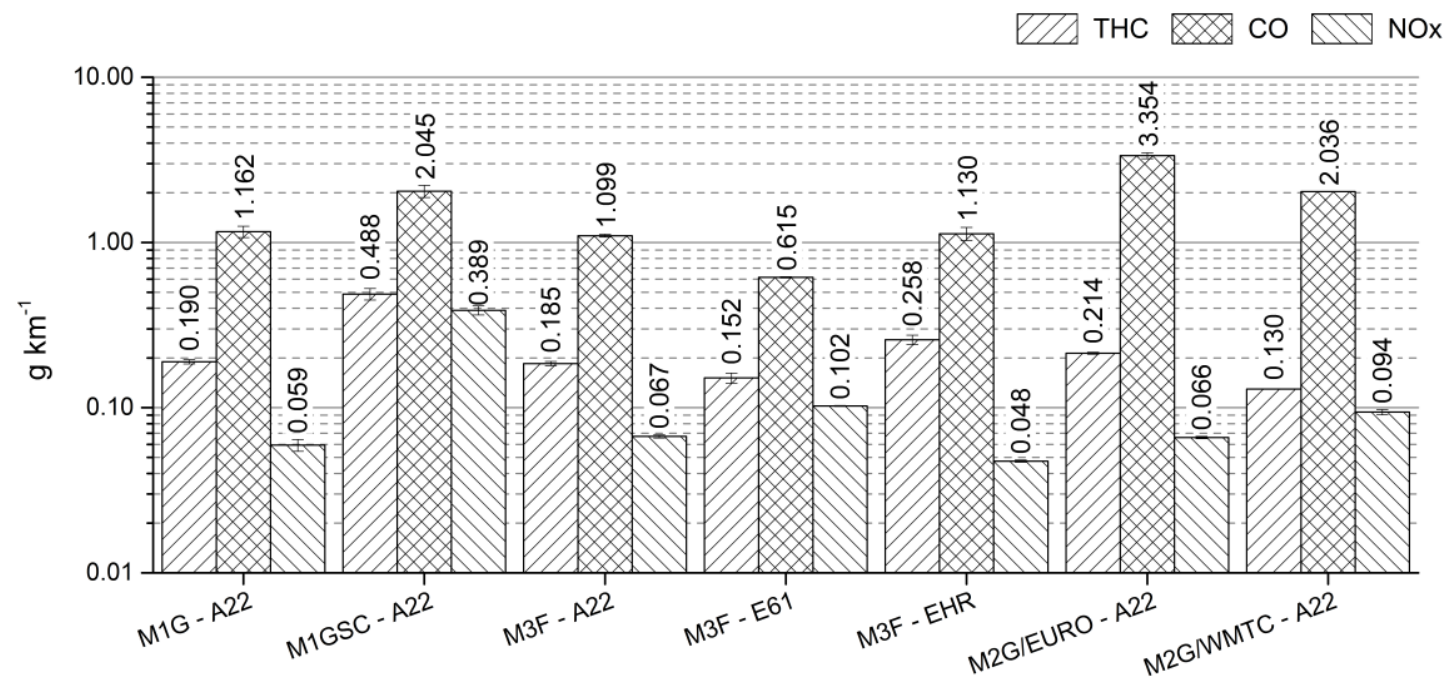

Figura 3 - Resultados de $\mathrm{THC}, \mathrm{CO}$ e $\mathrm{NO}_{\mathrm{x}}$

A figura 4 mostra um panorama geral dos resultados e tem o objetivo de evidenciar a relevância das emissões de BTEX quando comparadas com os hidrocarbonetos totais. Os valores expressivos dos BTEX ensejam que se deve tomar atenção a tais emissões.

Para o motociclo M3F foi observada uma emissão superior de BTEX ao total de hidrocarbonetos (THC) com uso de $\mathrm{A} 22$, resultado não esperado, visto que os compostos aromáticos pertencem ao grupo dos hidrocarbonetos. Porém o detector de hidrocarbonetos, que utiliza o princípio de ionização de chama, é calibrado com gás propano (com três carbonos) e o grupo dos BTEX possui de seis a oito carbonos, não sendo conhecido o fator de resposta desse detector para esses compostos. Esse fato pode resultar em erros de leitura para o THC, visto que os hidrocarbonetos emitidos durante a combustão do motor possuem diferentes constituições. Já na determinação dos BTEX 
por espectrometria de massas foram utilizados padrões específicos de cada composto, eliminando-se essa variável.

Na figura 4 observa-se ainda uma redução dos aromáticos (BTEX) com o aumento da participação do etanol na mistura devido a menor concentração desses compostos nesse combustível.

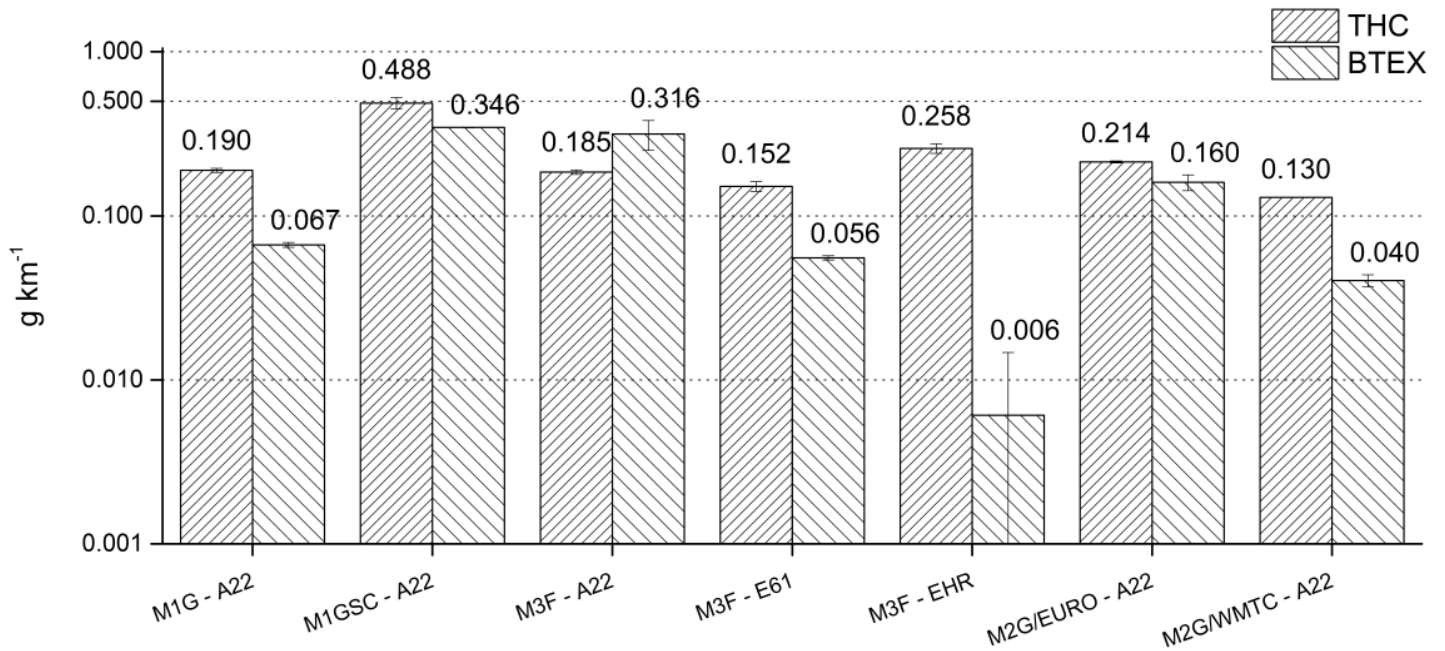

Figura 4 - Resultados de THC e BTEX nos três motociclos

A figura 5 mostra as concentrações de cada um dos aromáticos. Nela pode-se observar a preponderância do tolueno sobre os demais. Esse fato pode ser explicado observando os resultados dos BTEX presentes nos combustíveis, na tabela 1, onde constata-se que o tolueno apresenta a maior concentração quando comparado aos demais. Ou seja, a preponderância do tolueno nos combustíveis se reflete nas emissões gasosas geradas pelos motociclos.

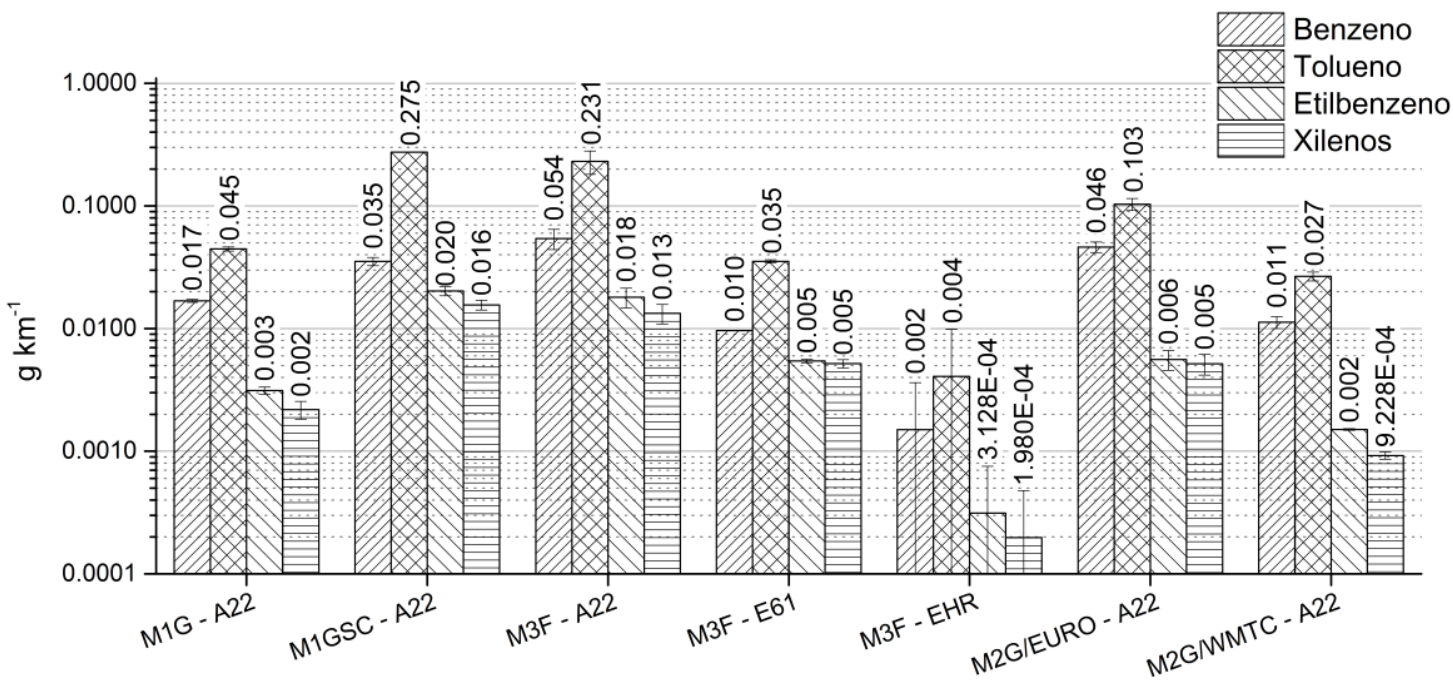

Figura 5 - Emissões de benzeno, tolueno, etilbenzeno e xilenos nos testes realizados nos três motociclos

A figura 6 mostra apenas os resultados obtidos no motociclo flexfuel, abastecido com três diferentes combustíveis. Verifica-se que o aumento do teor de etanol no combustível resulta na diminuição da emissão dos compostos aromáticos BTEX devido a menor concentração desses compostos no etanol. 


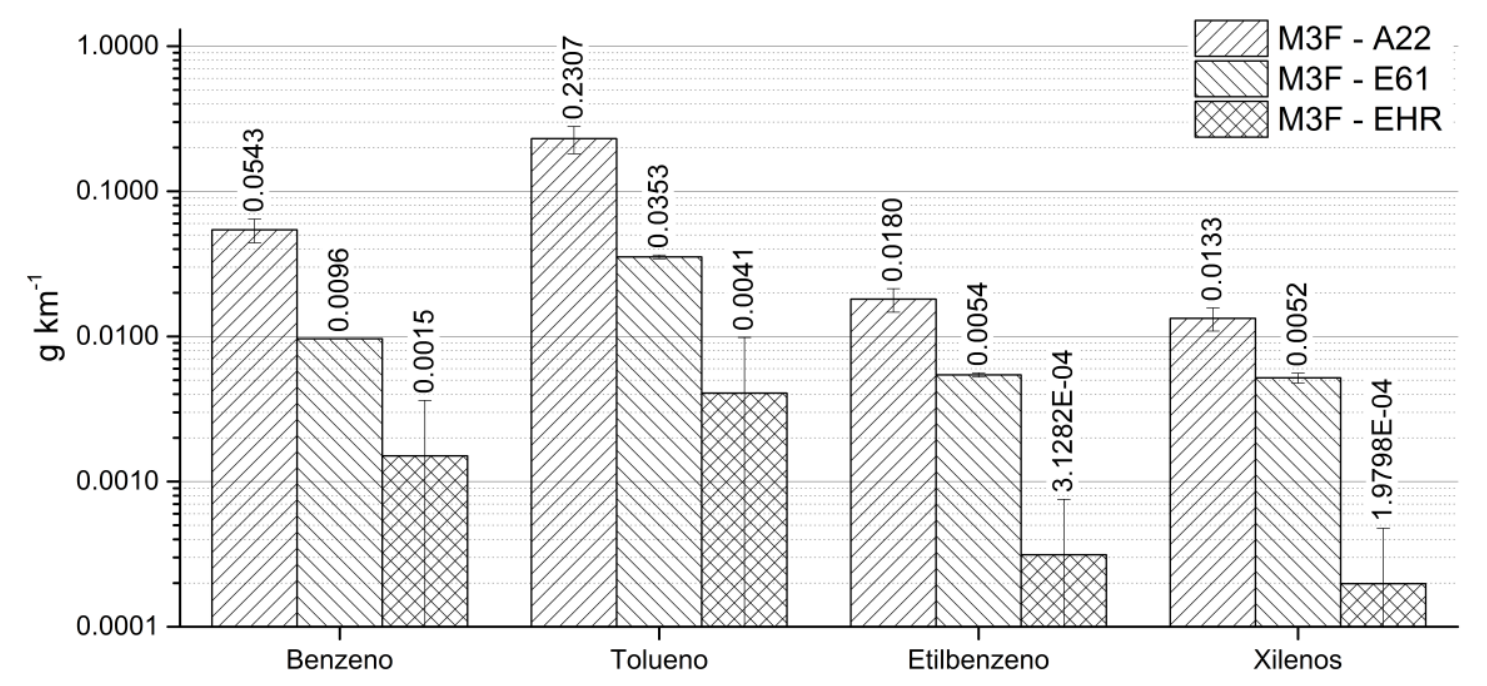

Figura 6 - Emissões de BTEX no motociclo flexfuel com combustíveis de diferentes teores de etanol

A figura 7 mostra uma comparação dos resultados obtidos após os ensaios do motociclo M1G com e sem catalisador (M1Gsc), com gasolina A22. A observação do gráfico permite concluir que o sistema de pós-tratamento (catalisador) possuí uma eficiência de conversão para as emissões desses gases de 52,3\% para o benzeno, 83,8 para tolueno, 84,6 para etilbenzeno e 85,98 para os xilenos. A menor conversão para o benzeno pode indicar que os demais compostos que possuem em sua estrutura química um anel benzênico e um radical perdem esse radical pela ação do catalisador gerando assim benzeno, o qual é composto apenas pelo anel benzênico.

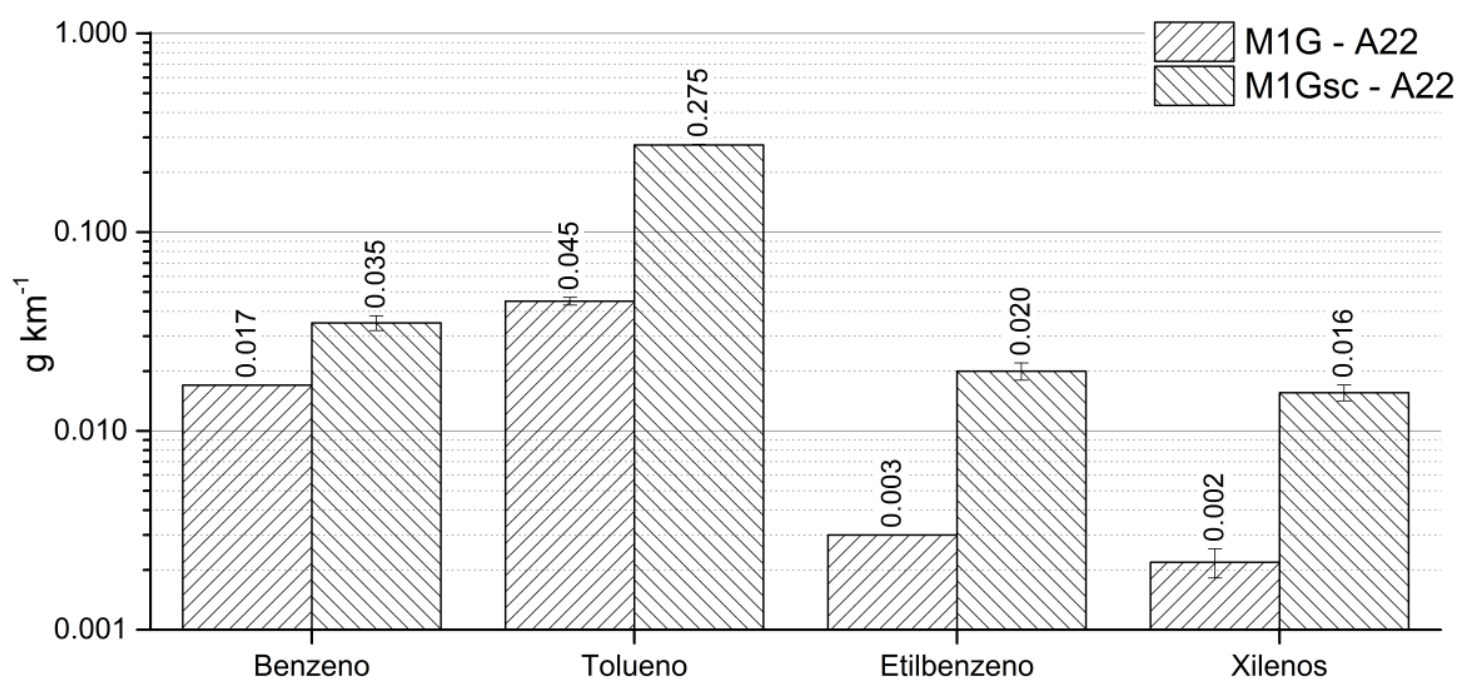

Figura 7 - Emissões de BTEX no motociclo M1 com e sem catalisador

O motociclo M2 foi ensaiado utilizando dos ciclos, EURO e WMTC, com gasolina A22. A figura 8 mostra os resultados das emissões legisladas e dos hidrocarbonetos do tipo não metano (NMHC) nos dois ciclos. Verifica-se que no ciclo WMTC as emissões de THC, CO e NMHC reduzem se comparadas com o ciclo EURO. Situação inversa acontece para os óxidos de nitrogênio. Isso ocorre, possivelmente, em função das características dos ciclos: tempo, aceleração e velocidades às quais o veículo é sujeito em cada ciclo, que são diferentes entre si. 


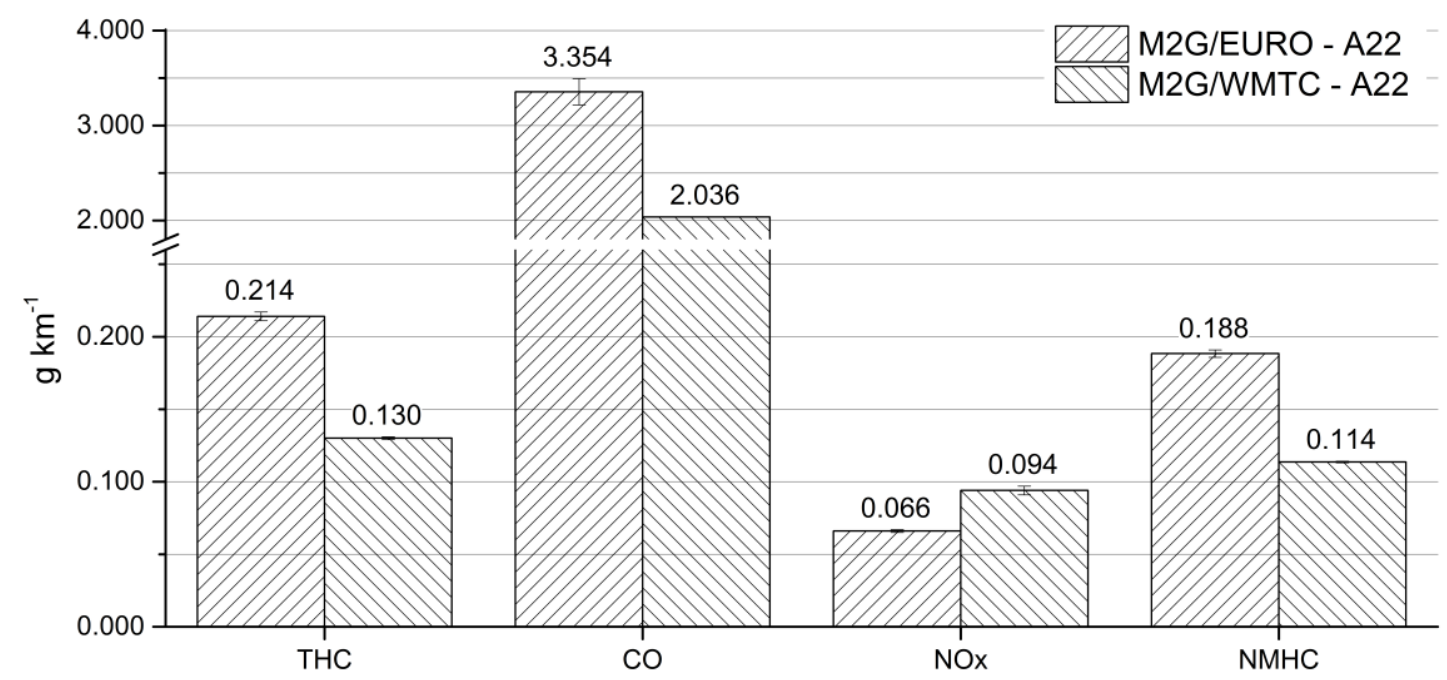

Figura 8 - Comparação das emissões legisladas obtidas nos ciclos EURO e WMTC

Na figura 9 são apresentados os resultados das emissões de BTEX (não legisladas). Observa-se uma situação semelhante à da figura 8 , onde as emissões no ciclo WMTC também são menores que no EURO. Tendência que pode ser justificada pelo fato de que os compostos BTEX serem derivados dos hidrocarbonetos (THC), que apresentaram redução nas emissões com aplicação do ciclo WMTC.

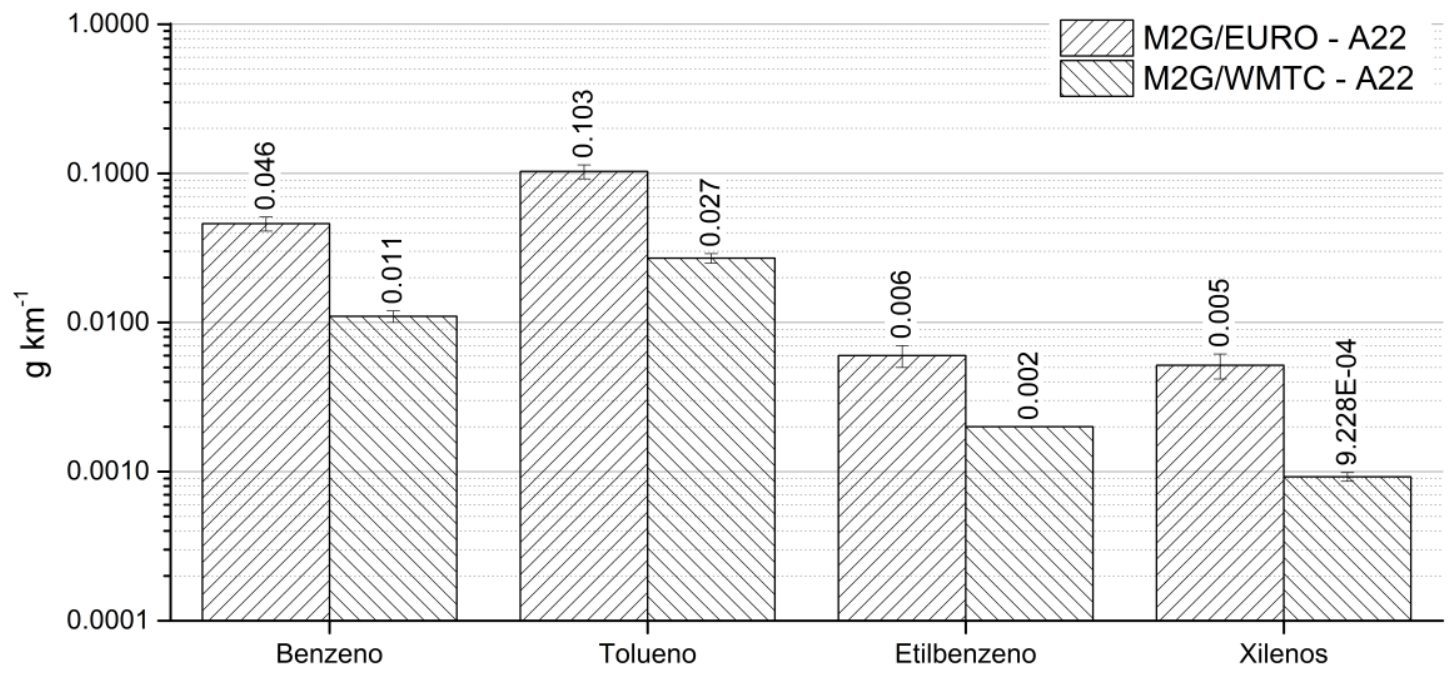

Figura 9 - Comparação das emissões de BTEX obtidas nos ciclos EURO e WMTC

\section{CONCLUSÃO}

A pesquisa bibliográfica realizada neste trabalho apontou a preocupação com o contato aos compostos BTEX devido à sua toxicidade com ênfase ao benzeno, por ser considerado cancerígeno. A legislação brasileira limita, através de regulamentos, a exposição de trabalhadores que utilizam esses compostos em sua rotina diária, porém atualmente não existem limites de emissões desses compostos pelos veículos automotores dotados de motor à combustão. 
O tolueno apresenta a concentração de emissão mais elevada com relação aos outros compostos do grupo, devido ao fato de possuir também a maior concentração na composição dos combustíveis utilizados. Estudos para a redução da concentração desse composto na gasolina devem ser considerados, sendo esse composto classificado como tóxico à saúde humana.

A comparação dos resultados dos ensaios realizados no motociclo flexfuel indica que a utilização de etanol é uma opção para redução das emissões dos compostos de BTEX. Os resultados permitem inferir que as emissões de BTEX estão diretamente ligadas com a concentração do etanol no combustível.

Um estudo mais aprofundado nas emissões de aromáticos com veículos abastecidos com etanol é necessário uma vez que, apesar da análise físico-química do etanol não haver apresentado valores detectáveis de concentração de aromáticos, os resultados das análises do escapamento da motocicleta M3F apresentaram valores de BTEX (mesmo em concentração pequena quando comparada aos outros combustíveis).

Quando foram comparados os resultados com os ciclos EURO e WMTC, foi possível observar que as emissões dos compostos THC e CO foram menores com o ciclo WMTC em relação ao EURO. Isso pode ser explicado pela diferença entre os ciclos que exigem de forma diferenciada o motor do veículo, Os resultados das emissões de $\mathrm{NO}_{\mathrm{x}}$ estão diretamente ligados com processo de queima na câmara de combustão. Este fator pode ter impactado no aumento do $\mathrm{NO}_{\mathrm{x}}$ e redução nos demais compostos. Considerando que os BTEX fazem parte dos compostos do grupo THC, os valores de análise também foram menores.

Sugerem-se estudos para determinar o fator de resposta do detector de ionização de chama (DIC) ao grupo dos compostos aromáticos (BTEX), com intuito de verificar se as emissões do total de hidrocarbonetos não estão sendo subestimadas pela metodologia atual.

Os resultados dessa pesquisa estão circunscritos às amostras utilizadas nos testes.

\section{AGRADECIMENTOS}

Aos Institutos LACTEC, em especial ao corpo técnico do LEME pela realização dos testes de laboratório que possibilitaram a elaboração desse estudo.

Ao Ministério da Ciência e Tecnologia e ao CNPq (Conselho Nacional de Desenvolvimento Científico e Tecnológico) pelo incentivo recebido com a aplicação da Lei 8010/90 nos Laboratórios do LACTEC.

\section{REFERÊNCIAS}

[1] MOOLLA, R.; CURTIS, C. J.; KNIGHT, J. Assessment of occupational exposure to BTEX compounds at a bus diesel-refueling bay: A case study in Johannesburg, South Africa. Science of the Total Environment, v. 537, p. 51-57, 2015. 
[2] CETESB. PCPV: Plano de Controle de Poluição Veicular do Estado de São Paulo. São Paulo,2013. 48 p. Disponível em: <http://www.cetesb.sp.gov.br/ar /documentos/Plano_de_Controle_de_Poluicao_Veicular_do_Estado_de_Sao_Paulo201 1-2013.pdf>. Acesso em: 05 set. 2013.

[3] DAEMME, Luiz Carlos et al. Emissions of Criteria and Non-Criteria Pollutants by a Flex-Fuel Motorcycle. Journal Of The Brazilian Chemical Society, p.01-11, 14 jan. 2016.

[4] BRASIL. MINISTÉRIO DO MEIO AMBIENTE, Resolução CONAMA nº 297.

Estabelecimento dos limites para emissões de gases poluentes por

ciclomotores, motociclos e veículos similares novos, 2002. Publicada no

DOU no. 51, de 15 de março de 2002, Seção 1, páginas 86-88.

[5] FERREIRA, S. L. et al. Analysis of BTEX in the emissions from an internal combustion engine burning diesel oil and diesel-biodiesel mixture (B10) by gas chromatography. Quimica Nova, v. 31, n. 3, p. 539-545, 2008.

[6] CASTRO, Bárbara Prestes de. Determinação de compostos monocromáticos voláteis provenientes de emissões de veículos leves, em estacionamentos subterrâneos.2011. 97 f. Dissertação (Mestrado) - Curso de Engenharia Ambiental, Departamento de Controle de Efluentes Líquidos e Emissões Atmosféricas, Universidade do Estado do Rio de Janeiro, Rio de Janeiro, 2011.

[7] MARC, M. et al. The influence of meteorological conditions and anthropogenic activities on the seasonal fluctuations of BTEX in the urban air of the Hanseatic city of Gdansk, Poland. Environmental Science and Pollution Research, v. 22, n. 15, p. 11940-11954, 2015.

[8] YAO, Yung-Chen et al. Effects of sulfur and aromatic contents in gasoline on motorcycle emissions. Atmospheric Environment, v. 42, n. 26, p. 6560-6564, 2008.

[9] Correa, S. M., Arbilla, G., Marques, M.R.C., Oliveira, K.M.P.G.. "The Impact of BTEX Emissions from Gas Stations into the Atmosphere." Atmospheric Pollution Research 3, 163-169, 2012.

[10] Li, Lan et al. Exhaust and evaporative emissions from motorcycles fueled with ethanol gasoline blends. Science of the Total Environment, v. 502, p. 627-631, 2015.

[11] DAEMME, L. C.; PENTEADO, R.; ERRERA, M. R.; ZOTIN, F. M. Z. Estudo preliminar sobre a influência do teor de enxofre do combustível na emissão de amônia em motociclos e veículos leves dos ciclos Otto e Diesel. Blucher Engineering Proceedings (SIMEA 2013). No. 1, Volume 1, fevereiro 2014.

[12] BRASIL. AGENCIA NACIONAL DO PETRÓLEO, GÁS NATURAL E BIOCOMBUSTIVEÍS, Resolução ANP $\mathrm{n}^{\circ}$ 6. Especificação da gasolina automotiva utilizada como padrão nos ensaios de consumo de combustível e emissões veiculares. Publicada no DOU de 25 de fevereiro de 2005 
[13] BRASIL. AGENCIA NACIONAL DO PETRÓLEO, GÁS NATURAL E BIOCOMBUSTIVEÍS, Resolução ANP $\mathrm{n}^{\circ}$ 7. especificações do álcool etílico anidro combustível ou etanol anidro combustível e do álcool etílico hidratado combustível ou etanol hidratado combustível. Publicada no DOU 10.2.2011 - RETIFICADA DOU 14.4.2011. 